\title{
Nodes Activation Strategies of Pedestrian System in Rail Hub Areas: Taking East Asia for Example
}

\author{
Liang Wu, Wei Lu, Zongchao Gu \\ School of Architecture and Fine Art, Dalian University of Technology, Dalian, China \\ Email: wuliang1026@126.com
}

How to cite this paper: Wu, L., Lu, W., \& $\mathrm{Gu}$, Z. C. (2018). Nodes Activation Strategies of Pedestrian System in Rail Hub Areas: Taking East Asia for Example. Current Urban Studies, 6, 401-411. https://doi.org/10.4236/cus.2018.63021

Received: July 23, 2018

Accepted: September 22, 2018

Published: September 25, 2018

Copyright $\odot 2018$ by authors and Scientific Research Publishing Inc. This work is licensed under the Creative Commons Attribution International License (CC BY 4.0).

http://creativecommons.org/licenses/by/4.0/

\begin{abstract}
Urban rail transit has been developed rapidly in high density cities in East Asia. The node space of the pedestrian system in the rail transit hub area is the main carrier of the social public life, but its performance in usability and readability is negative. Based on the recent development cases in many cities of China and Japan, this paper puts forward the modes and approaches of node activation from three aspects of aggregation, ecology and humanity, which can be used as a reference for urban vitality promotion in the rail transit hub area.
\end{abstract}

\section{Keywords}

Rail Transit Hub, Pedestrian System, Node Space, Urban Vitality

\section{Introduction}

For the cities of East Asia which are famous for their high density, the Car-Dominated traffic mode is hard to adapt to traffic demands of a huge population in a limited space. In many cities, the roads and parking places have squeezed the space for walking and public activities to an extent of intolerance. Even so, the number of cars is still growing, and traffic congestion is becoming more and more serious. Therefore, changing the traffic mode and developing urban rail transit system represented by metro are the main development trend of high density Asian cities, which is of great and positive significance to solving urban problems of traffic, environment and energy (Calthorpe et al. 2014).

Taking China for example, from 2000 to 2016, the number of cities operating metro in Mainland China raised from 4 to 27, and the operating mileage raised 
from $119.33 \mathrm{~km}$ to $3172.78 \mathrm{~km}$ (Wu, 2018). The metro network of Beijing and Shanghai had basically taken shape until the end of 2016, which scale approximately accounts for $37 \%$ of that of the whole Mainland China, while the metro operating mileage of most cities is less than $100 \mathrm{~km}$ and their metro network is still in the process of being fast weaved.

The dual function of traffic transfer center and public activity center of rail transit hub areas makes them become one of the areas with the highest intensity of walking activity. The driving effect of rail transit hub to urban development is on the basis of walking accessibility, so pedestrian system is the key elements of high quality, high efficient and sustainable development of rail transit hub areas.

\section{Problems}

Pedestrian system has multiplicity in essence, it is not only a kind of traffic facilities and urban space, but also it is a kind of important public resource in the social sense and the foundation of most social life (Figure 1). In current cities, a real contradiction is that, the more public function centralization of high-density urban centers, the more scarce and single resources of public walking space, so that the social public life has lost the foundation. Most of the pedestrian systems are only the passageway for the flow of people, and the behaviors such as shopping, staying, communicating and so on, can't be effectively supported by pedestrian systems. Although the block is busy as a result of the high density of the population, it lacks the nature of the diversity of urban life, showing the characteristics of the mechanical space, but not the characteristics of the dynamic city space (Xu et al. 2015). This situation has been paid attention to in the era of "Automobile City" and criticized by all walks of life. In fact, this is one of the causes of the new urbanism theory, represented by TOD. The state of use and perception of space have an important impact on the shaping of social public life, while the performance of the pedestrian system in rail transit hub areas in these two aspects are all negative, and there are obvious deficiencies in usability and readability.

\subsection{Usability}

Usability refers to the possibility that all kinds of spatial elements in a pedestrian system are used in some or more ways, specific to the social public life level, which represents the support of the pedestrian system to social interaction.

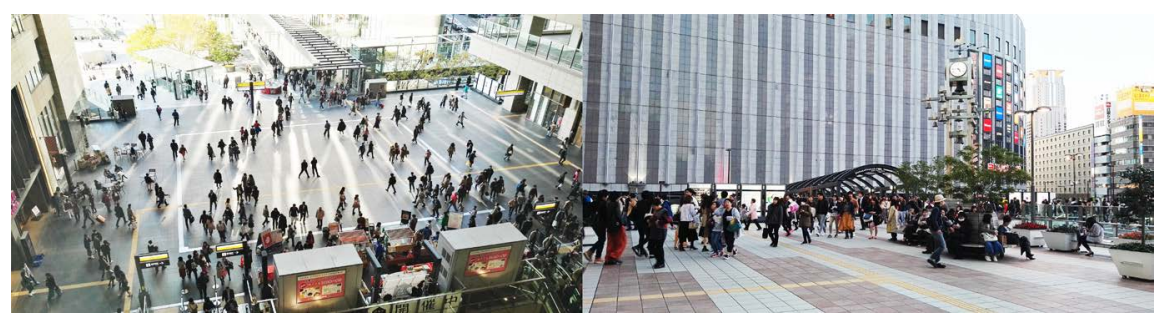

Figure 1. Pedestrian system in Osaka Station area. 
Vikas Mehta defines a social street in "street: the social public space" as "open streets, people present in the streets for most of the time. They are involved in a series of active or passive social behavior in the form of individuals or in a collective form, which are essentially quiet state and continuity" (Mehta, 2016). The relative "static" social interaction and the "dynamic" walking traffic should be the main content of the pedestrian system in station areas, and the former is the real root of the city's vitality.

However, the "node type" public space has been ignored in the planning and design of the pedestrian system in station areas directly inherited from the "car city", resulting in the lack of the number of nodes, the single mode and low quality and so on. Most of the so-called node space is actually a distributed space attached to public facilities (especially commercial facilities). It is close to the noisy urban road and has no systematic planning and fine design on the space scale, level and theme. Because of the lack of attention to all kinds of users and their psychological needs, including the disadvantaged groups, these spaces can't attract or even exclude all kinds of resident activities. Most public spaces are reduced to negative spaces only for people to pass through, and they almost lose their social functions, let alone to support the diversification of public life.

\subsection{Readability}

Readability refers to the degree of acceptance, understanding and recognition of walking space from the user's cognitive and emotional level. Unlike the external behavior patterns expressed by usability, readability is related to the user's psychological activities, which are produced on the basis of usability and in the association mapping between object space and subjective perception. Saying of the problems of urban road in car era, Ma Qiang thinks that in fact, the urban road, in addition to the traffic function, also carries a lot of other functions (such as business, meeting, recreation and so on), which is the main public space for urban life and human communication, and it needs to wake people's sense of street life (Ma, 2007).

The rail transit hub area is often one of the most modernized areas in the city with the most thorough transformation of the original environment. Compared with traditional space, modern urban space may have higher capacity and efficiency, but at the same time, it can also eliminate the differences between them. The public space has lost the natural connection with the specific region and cultural background. The spatial personality and characteristics are desalinated, disappearing, or only in the symbolic and rigid expression. The relationship between human and space is simplified as the relationship between the use and use, the sense of domain, participation and belonging are generally missing, and it is difficult to produce an emotional resonance.

\section{Strategies}

Pedestrian system is not only urban space, but also social space. It is a transpor- 
tation network as well as a life network. In the rail transit area, the pedestrian system is the main place to support the social public life besides the traffic function of the human flow and transfer, and the diversified public activities are the source of the vitality of the urban space. Based on the theory of Space-Behavior, the occurrence of public activities is based on the interaction between the specific place environment and the public demand, and the space place which can respond to the public needs is the basic prerequisite for the occurrence of public activities. Under the "inspiration" of the place environment, the latent demand and the "chain" social activities are more easily triggered, so that the vitality of the place can be sustained.

The "node activation" strategy is mainly a micro construction strategy of pedestrian system proposed on the quality dimension. The core of the strategy is to build a series of space places with the cohesive and living atmosphere from the individual and social needs of the walker and the specific environmental texture and context, and form the "active" nodes in the walking space network of which public activity is the main content, to realize the complementation of life function and traffic function, and enhance the walker's spatial experience and identity.

The basic way of "node activation" is to enhance its environmental quality through the organic infiltration of "active" elements into the physical space, and the "active" elements are derived from the texture and context of the physical environment, the natural environment and the human environment where the node space lies. Therefore, the "active node" has a diversified form of generation and construction. This paper divides it into three aspects: Aggregate Node, Ecological Node and Humanistic Node.

\subsection{Aggregate Node: Symbiosis of Dynamic and Static Space}

The aggregation of people is the most direct factor for all kinds of social activities. Therefore, the aggregated stream of people is the first "active element" in the "node activation" strategy. According to Bill Hillier's Configurational theory, the spatial structure relationship has a significant influence on the land use and the distribution of human flow. The high integration space represents a good accessibility, strong cohesive force and a higher probability of human flow aggregation. It is deduced that the space nodes with high integration due to internal structure attributes and external relations will become the center of human flow aggregation in the pedestrian system in rail transit hub areas, which is called "aggregate node". The aggregation node that only carries the traffic function is not equal to the active node, and the aggregate node with life function can produce and maintain the vitality of the space.

In pedestrian system, static living node and dynamic traffic node have obvious complementation in function. Through the coupling of space, the traffic node improves the accessibility of the life node, thus increasing the efficiency of its use; the life node enhances the vitality of the traffic node, and provides space 
support for the diversified social demand. This combination of dynamic and static can realize the symbiosis of mobility and retention, and make the double node become the integrated "aggregate node" with strong centrality, and often become the symbol space of the core area of the rail transit hub.

In the design of a new large-scale development project, "Tokyo Midtown Hibiya", in the Hibiya Metro Hub Area, the original road was transformed into a walking space through the adjustment of the land division, and an "aggregate node", Hibiya Gate Plaza, is created for crowd gathering and communication in the intersecting position of the metro passengers' main flow lines and the main entrance of large commercial facilities through the integration of private development and public land, which becomes the vitality center of the whole regional pedestrian system (Yoshida, 2017) (Figure 2).

In addition to the combination of large commercial facilities, the station square of large rail facilities is also a representative type of aggregate node in the Metro Hub area complex with urban traffic portal, which is not only the main distribution space, but also has rich living function. The station square not only needs to pursue the "traffic node function" with the aim of traffic, but also needs to pursue the function of square as the symbol of the city and the exchange stage (Nikken, 2014). For example, in the YAESU redevelopment project of Tokyo station, by increasing the depth of the square, adding two layers of overpass and the big roof of the membrane structure, the function of the traffic node of the station square is strengthened and the environmental quality of the resting place has been improved, and the symbolic space of the greenery is filled (Figure 3).

\subsection{Ecological Node: Connectedness of over and under Ground Space}

Natural elements are scarce resources of the built environmental system in metro hub areas, but they are of great significance to improve the ecological quality of the walking space and create a comfortable walking environment. The high density development of the building facilities reduces the afforested area of the

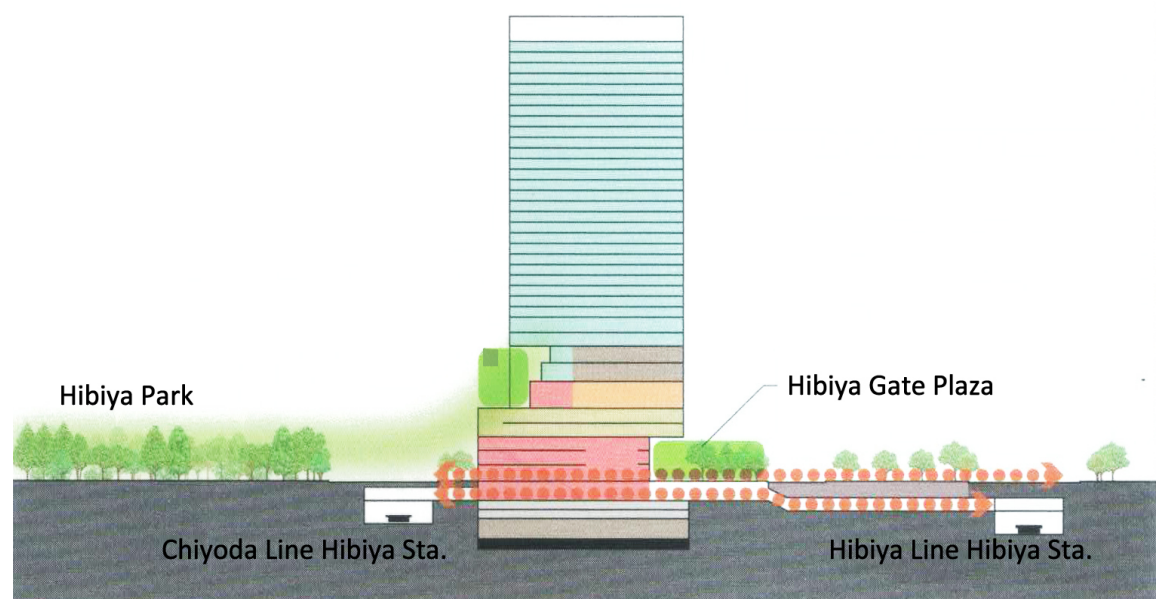

Figure 2. Hibiya Gate Plaza, Tokyo. Source: Yoshida, 2017: p. 160-161. 


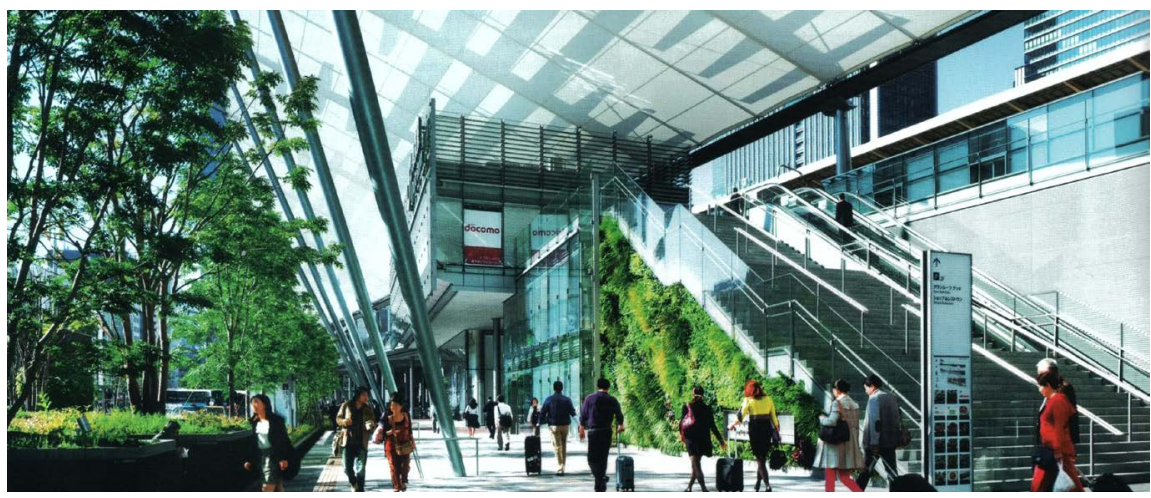

Figure 3. YAESU Square of Tokyo Station. Source: Yoshida 2017: p. 104.

surface, and the development of the walking base from ground to underground and the air further leads to the departure of the walking space from the natural environment. In the key node area of the multifaceted pedestrian system, the three-dimensional living space is opened up and the natural environmental factors such as vegetation, water body and sunlight are concentrated. It can not only beautify the walking environment from the landscape, but also improve the microclimate in the local area, cut off the traffic noise, increase the biological diversity and enhance the comfort of the place experience, thus becoming an effective way to attract the pedestrians to stay and promote the social activities.

In accordance with the three-dimensional characteristics of urban space in the rail transit hub area, the introduction of natural elements should be taken into account from the underground to the air in the construction of the pedestrian system.

- The underground space should increase the possibility of natural lighting and ventilation by interspersing the sinking open space at the key nodes and setting up a variety of lighting skylights in combination with the ground landscape.

- In the ground pedestrian system, the introduction of natural elements should take "continuous integration" as the main direction. On the basis of protecting existing resources, the continuous natural ecosystem should be formed through the introduction of the missing natural elements in the main path and node space.

- The walking public platform in the air level should make full use of its lighting and ventilation advantages, combining the technological innovation of "planting roof" and "water storage roof", and creating a kind of "ground like" public space environment through the diversified combination of water and plants.

The overall continuity of the natural elements in the built environment not only affects the dynamic spatial experience of the pedestrians, but also the necessary guarantee for the maintenance of a regional ecosystem with biodiversity. Therefore, in addition to introducing specific natural elements in all levels of the pedestrian system, we should pay more attention to the continuous infiltration 
of natural material elements, such as vegetation, water, and so on. For example, through the retreating or vertical greening in interlayer conversion nodes, the ground greening system can be extended to the ground and in the air to form a "three-dimensional tour forest" which combines green system with the moving line system.

The Futako Tamagawa Rise is a typical case of stimulating the vitality of the pedestrian system through the creation of ecological nodes. After more than 30 years of promotion and implementation, the project has completed the integrated urban design of the three blocks in the south of the station, and constructed a 1 kilometer continuous walking path from the station to the Futako Tamagawa park on the 2nd floor surface, and set up a series of roof gardens and grass squares. The ecological landscape of continuous construction combines the abundant natural environment elements such as the existing rivers, valleys and parks in the region into a diversity of biological community, which draws the distance between the human and the natural environment, as shown in Figure 4.

Although in general, the "ecological node" of the pedestrian system in rail transit hub areas of China Mainland is short, but in some new development practice, it has also begun to attach importance to the construction of the three-dimensional ecological environment. The most recent representative case is "Shanghai Greenland Center/Greenland Being Funny", which is in the core of Longhuazhong Road Station area in Shanghai. The Longhuazhong Road Station is the transfer hub of two metro lines. This program is located above the metro station. It is a complex development project, which includes large commercial facilities and three high-rise towers of office and SOHO. It opened in April 2017. The designer puts forward the concept of "green land", which makes the top of a number of continuous commercial facilities green and creates a "Green Valley". Through large slant green space, the station passengers are guided to the air platforms from the ground, and the metro station, the bus hub, the business entrance, the office entrance and so on are connected together. The integration of multi level living space and natural environment based on metro station is realized, as shown in Figure 5.

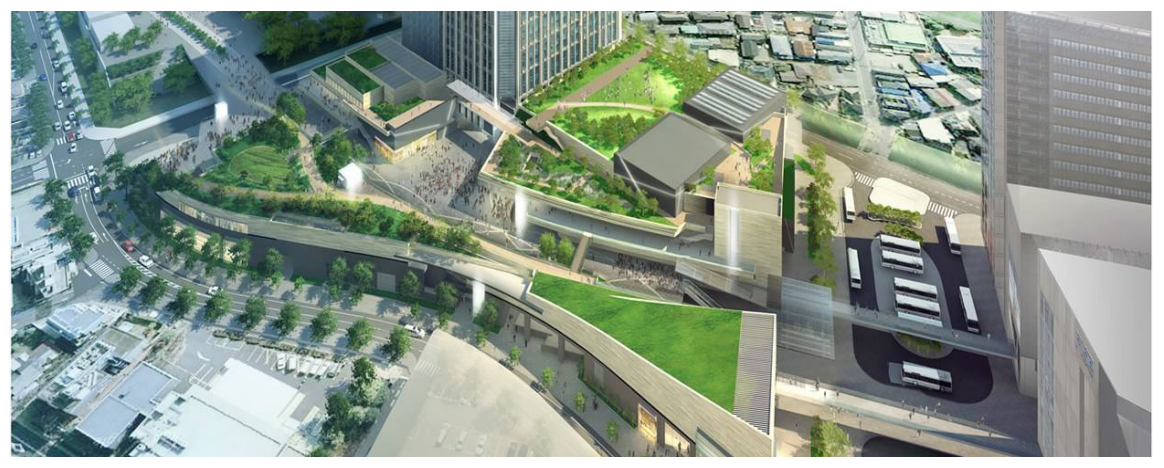

Figure 4. Three-dimensional ecological space in Futako Tamagawa Station area. Source: http://www.sohu.com/a/151126696_99924247. 


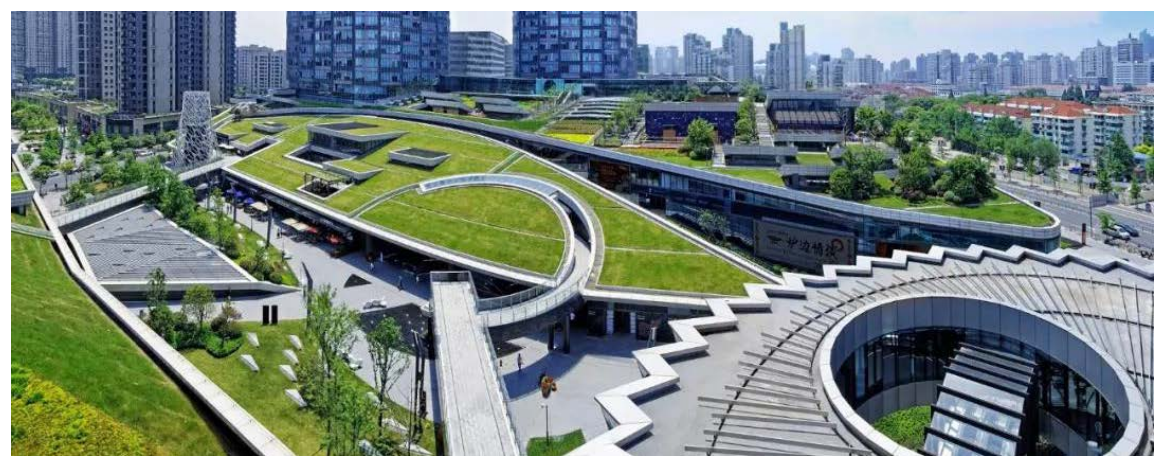

Figure 5. Three-dimensional ecological space in Longhuazhong Road Station area. Source: WeChat: NIKKEN, 2018.04.11.

\subsection{Humanistic Node: Combination of the New and Old Place}

In addition to the urban elements and natural elements, the human elements rooted in the deep structure of the city are also one of the "active elements" to stimulate the space vitality of the pedestrian system in rail transit hub areas. The walking environment with good humanistic quality can trigger the "emotional resonance" of the pedestrians, so as to promote active and dynamic social life, and meet the spiritual needs of pedestrians at a higher level. Therefore, in the construction of the pedestrian system in rail transit hub areas, creating a variety of "Humanistic nodes" has become one of the most important ways to improve the overall space vitality of the pedestrian system.

"Cultural gene" is a "marked" factor formed in the long process of development, based on unique geographical and historical conditions. It is the key factor to shape the "identity" of the city, as well as a space place with a sense of belonging and identity. It has both the tangible and dominant "gene", and the invisible and recessive "Gene". It is one of the main strategies of constructing $\mathrm{Hu}$ manistic Node to transfer and translate urban "cultural genes" in the aspects of spatial patterns, symbols and images.

In the construction of the pedestrian system, the historical remains of special landscape and cultural value, as the dominant "cultural gene", can provide a rare opportunity for the creation of characteristic and dynamic walking space nodes. In the process of urban development and renewal, it should be protected and utilized, and integrate its location into a part of the walking system through the connection with the main walking path, and increase the opportunity to be used and experienced; through the protection planning and regenerative design, it can be transformed into a "boundary" or "Center" elements to create "enclosed" or "controlled" public space nodes. For more rail transit hubs which belong to the non historical cultural center, the recessive "cultural genes" can be transformed into the perceptible "theme elements" integrated into the node construction of the pedestrian system through the operation of extraction, translation and reproduction to create a series of characteristic space fields with structural diversity and image continuity. 
Whether the symbolic space formed based on the "dominant gene" or the theme space formed based on the "recessive gene", the humanistic nodes should pay more attention to the humanization design in the space details in addition to the introduction of "culture", such as the suitable space scale which is neither crowded nor open, the friendly facilities faced to all use groups and the multi-level spatial domain adapting to various activities. These problems of walking space design which belong to the micro level are mostly universal and basic. They are not unique to the rail transit hub areas, and they themselves are the big research topic. It is not much discussed in the scope of this study, but it should be particularly pointed out that the activation of the overall vitality of the pedestrian system ultimately depends on every "active unit" just as the relationship between the life body and the cell, and it should not and can't be divorced from the humanization design of each space.

In Jimbocho Hub area of Tokyo with many historical buildings, the new urban development pays special attention to the protection and utilization of historical buildings. For example, in the development of the Terrace Square in the southeastern part of Jimbocho Station, the protection of the historic building, Hakuhodo Head Office Building built in 1930, became the focus of the design. The components of the old buildings were dismantled and repaired one by one. The original street of the base was transformed into parks, and it was integrated with the surrounding space into the characteristic node of the pedestrian system, the garden plaza. The renovated Hakuhodo headquarters is located at the center of the site, facing the garden plaza and becoming a vital landmark that transmits the history of the district (Yoshida, 2017), as shown in Figure 6.

The Shanghai Jing'ansi metro hub is also a representative case in Chinese mainland cities. The development of its station area is closely related to the important cultural heritage of "the ancient temple of Jing'an - Jing'an Park", and the ecological, efficient and three-dimensional Jing'an Temple Plaza is designed through the strategy of Combination of The New and Old Place between the ancient temple and the park. The core of the plaza is a sinking square with an area of about 2800M2. The semicircle amphitheater and multi-functional large steps have been set up, which become the most important and most dynamic "Humanistic node" of the pedestrian system in the station area ( $\mathrm{Lu}$ et al., 2000), as shown in Figure 7.

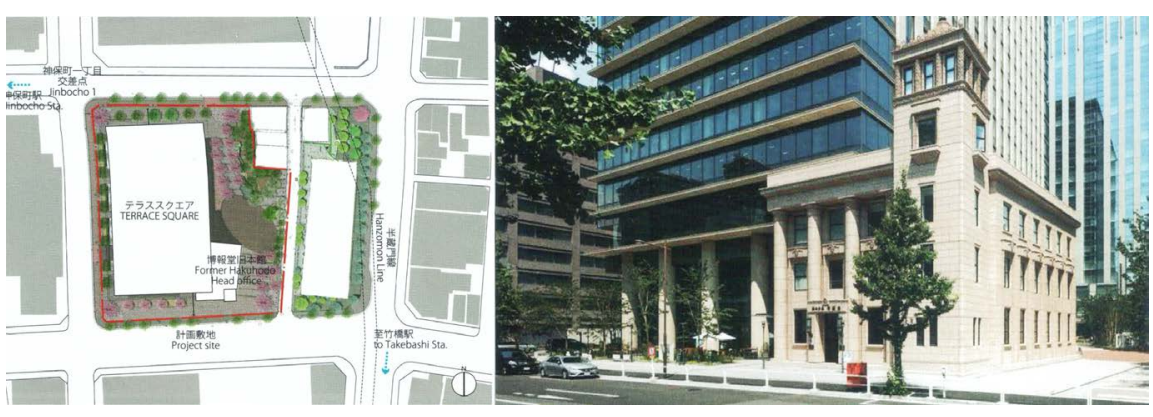

Figure 6. Terrace Square in Jimbocho Hub area. Source: Yoshida, 2017: p. 137. 


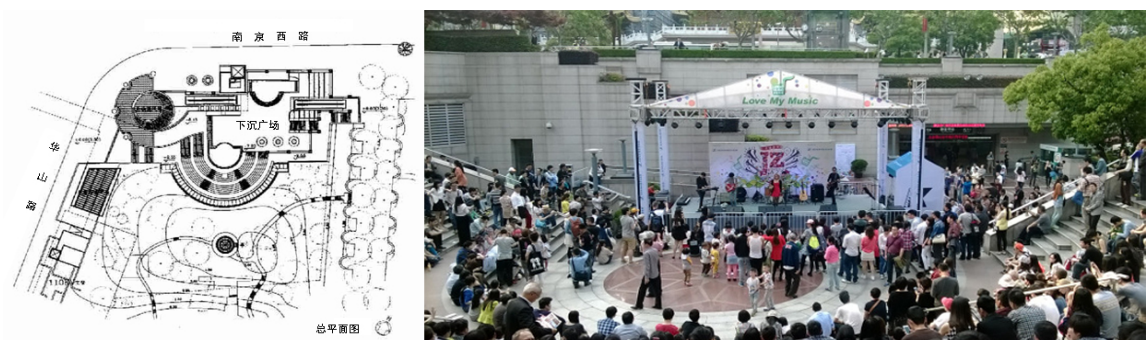

Figure 7. Jing'an Temple Plaza in Jing'ansi Hub area. Source: Lu et al., 2000 \& http://www.dianping.com/photos/47900887/member .

\section{Conclusion}

The state of public life is the direct embodiment of the degree of social civilization. More and more attention has been paid to the personalization and socialization of human beings. To create more and more suitable places for social public life has become one of the main tasks of urban design. The high accessibility, openness and public nature of urban space make the rail transit hub area one of the regions with the highest population density, the most social activities and the longest duration in Asian cities, and the node space of the pedestrian system is the main stage to support and encourage the social public life in the rail transit hub area. In the face of the problem of availability and readability existing in the current node space of pedestrian system in urban rail transit station, this paper proposes three main strategies for node activation.

- To make use of the aggregation effect of crowd flow and create a static living place combining the entrance space of large public facilities.

- To create three-dimensional living space, introduce natural elements at all levels and enhance their ecological continuity.

- To inherit or translate urban historical culture genes and reflect the organic difference and recognition of pedestrian spaces.

From the mode of behavior, the social public life in both the building and the urban space is walking activities. Compared with the interior space of the building, the social public life in the node space of pedestrian system is more diversified and universal, and the social effects and values are more significant. The improvement of service level, ecological level and humanistic quality of node space through urban design is of positive significance to stimulate urban vitality and maintain social harmony in the rail transit hub areas. Based on the characteristics of urban environment in Asia, the node activation strategies, which are proposed from the different dimensions of artificial, natural and social, provide an urban design method for optimizing the spatial structure, improving the living function and improving the place quality of pedestrian system in rail transit hub areas. This research has important application value in the urban renewal of the station areas.

\section{Conflicts of Interest}

The authors declare no conflicts of interest regarding the publication of this paper. 


\section{References}

Calthorpe, P., Yang, B. J., Zhang, Q., et al. (2014). Transit Oriented Development in China: A Manual of Land-Use and Transportation for Low Carbon Cities (1st ed.). Beijing: China Architecture \& Building Press.

Lu, J. W., Gu, R. Z., Sun G. L., et al. (2000). Ecological, Effective and Three-Dimensional Public Space in the Downtown: Jing'an Temple Plaza of Shanghai. Time Architecture, 3, 58-61.

Ma, Q. (2007). A Road to "Smart Growth": From Auto-Dependent City to Transit-Oriented City. Beijing: China Architecture \& Building Press.

Mehta, V. (2016). The Street: A Quintessential Social Public Space. Beijing: Publishing House of Electronics Industry.

Nikken (2014). Integrated Station-City Development: The Next Advances of TOD. Beijing: China Architecture \& Building Press.

Wu, L. (2018). Study on the Adaptation Theory and Method of Pedestrian System in Metro Hub Areas. Ph.D. Thesis, Dalian: Dalian University of Technology.

Xu, K., Sun, T. Y., Han, X. F., et al. (2015). Pedestrian and Transit Hybrid. Shanghai: Tongji University Press.

Yoshida, N. (2017). Urban Activity, NIKKEN-Rethinking Livable Place Making. Tokyo: Shinkenchiku-SHA CO., LTD. 